\title{
Development of components of electro-optic modulators on a semiconductor substrate for microwave photonics
}

\author{
S.V. Ishutkin ${ }^{1}, I . V$. Kulinich $^{2,3, *}$, and R. Shageev ${ }^{2}$ \\ ${ }^{1}$ Tomsk State University of Control Systems and Radioelectronics 40, prospect Lenina, 634050, \\ Tomsk, Russia \\ ${ }^{2}$ Micran, 51d Kirova Avenue, 634041, Tomsk, Russia \\ ${ }^{3}$ IAO SB RAS, 1 Academician Zuev square, 634055, Tomsk, Russia
}

\begin{abstract}
The results of research and development of components of Mach-Zehnder electro-optic modulator, in particular, the Y-divider and MMI divider are presented. Technological studies were carried out and an optical divider on an InP semiconductor substrate was obtained.
\end{abstract}

\section{Introducrion}

The tendency of increasing the speed and volume of transmitted information has given the development to optical systems, particularly, to radio-photonics. One of the basic elements of the radio-photon section is an electro-optic modulator (EOM). For high-speed data transmission systems electro-optic modulators are manufactured on LiNbO3, GaAs, and InP substrates. The fabrication of EOMs on semiconductor substrates allows to reduce the geometrical sizes of device by several times compared to EOMs based on LiNbO3, as well as reduce the half-wave voltage, which extends the functionality of telecommunication equipment [1]. There are no EOM technologies on Russian market, and the number of publications of this topic proves that Russia has a lag in the area of radio-photon technologies.

One of the problems of EOM fabrication on a semiconductor substrate is great optical losses in device structure. Inaccuracies of the lithographic process makes a big contribution to the losses. Solutions presented in this paper aimed to reduce the insertion loss on the elements of the Mach-Zehnder electro-optic modulator on an InP substrate are relevant and are of great scientific interest.

\section{Experimental}

The structure of the Mach-Zehnder electro-optic modulator includes an optical divider and an optical connector. To date, a Y-divider and a divider based on a multimode interferometer (MMI) in the form of a ridge waveguide (Fig. 1) are used in integrated design [2].

*Corresponding author: kulinich@micran.ru 


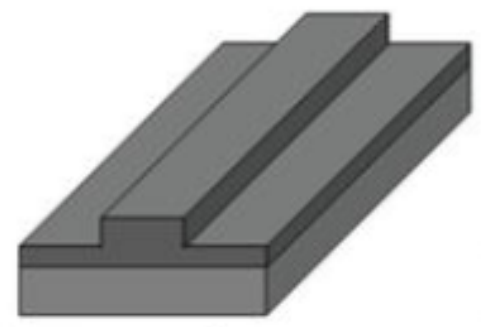

Fig. 1. Layout view of a ridge waveguide.

One of the main problems of MMI divider and the Y-divider fabrication is the reproduction of the required sizes. The simulation results showed when the sizes varies to $0,2 \mu \mathrm{m}$, the reflection coefficient can deteriorate by $20 \%$. One solution is to use electrical adjustment.

According to published data, using of additional electrode allows locally changing the refractive index by 0,01 [3]. In this connection, studies were conducted and designs of Yand MMI dividers with a control electrode were developed.

$\mathrm{T}$ he studies were carried out using mathematical modeling in 2D mode. Since the optic waveguide on the InP substrate was made as a ridge pin structure, most of the light propagates in the ridge volume (Fig. 2).

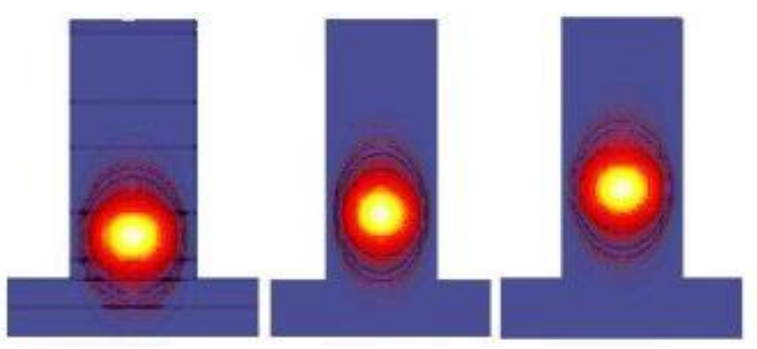

Fig. 2 . Layout view of light propagation in a ridge waveguide.

The optimal geometry calculated in [4] was chosen for Y-divider. The width of the control electrode was equal to the width of the waveguide and equal to $2 \mu \mathrm{m}$. The length of the electrode was varied in order to achieve the greatest difference in the separation of the electromagnetic wave. The location of electrode is shown in Fig. 3.

$$
\text { electrod } 100 \mathrm{mkm}
$$

Fig. 3. Model of a Y-divider with a control electrode.

Electromagnetic radiation with a wavelength of $1550 \mathrm{~nm}$ was applied to the input of the waveguide. The radiation was input orthogonally. Fig. 4 shows the dependence of transfer coefficients between the channels from length of control electrode.

The results of studies showed that we can achieve the adjustment of the division coefficient to $20 \%$ for the selected geometry of divider and control electrode. Also, studies of MMI divider with a control electrode were conducted.

The electrode size varied from 6 to $36 \mu \mathrm{m}$ in the model, and the change of proportion of light wave division in the interferometer was compared. Fig. 5 shows a model of multimode interference divider with an electrode of $6 \mu \mathrm{m}$ in length. 


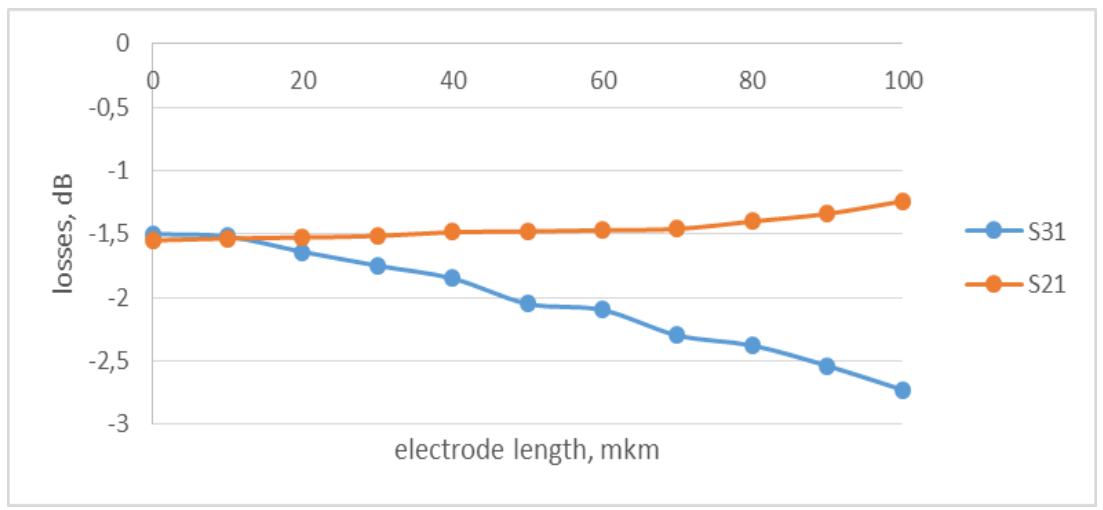

Fig. 4. The dependence of transfer coefficients from length of control electrode.

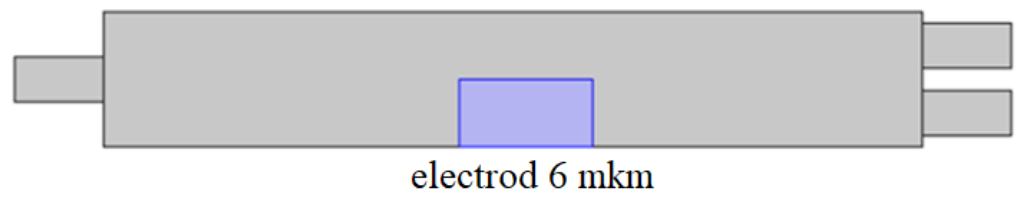

Fig. 5. Model of multimode interference divider with an electrode of $6 \mu \mathrm{m}$ in length.

Fig. 6 shows a model of multimode interference divider with an electrode of $36 \mu \mathrm{m}$ in length.

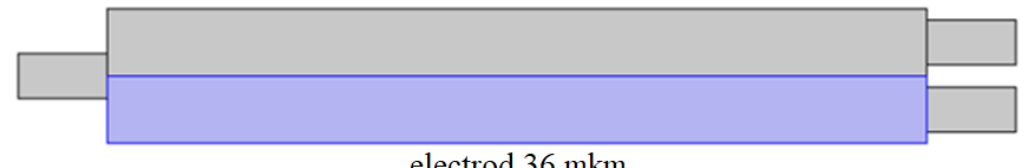

electrod $36 \mathrm{mkm}$

Fig. 6 . Model of multimode interference divider with an electrode of $36 \mu \mathrm{m}$ in length.

Fig. 7 shows the dependence of transmission coefficient $\mathrm{T}$ on the second and the third ports from electrode length 1 .

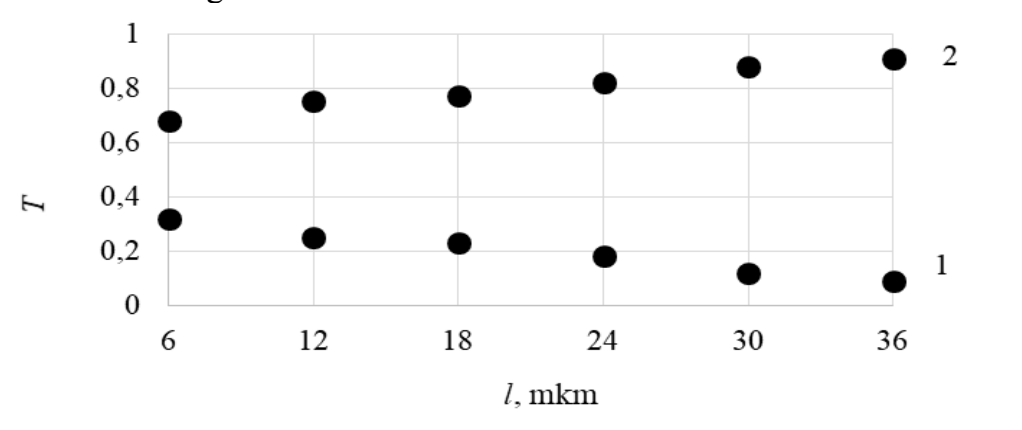

Fig. 7. The dependence of transmission coefficient $\mathrm{T}$ on the second and the third ports from electrode length 1: 1) - T2;2) - T3.

Figure shows that increase of electrode length results in increase of difference in transmission coefficients of light wave in MMI divider.

To confirm the possibility of adjustment of optic dividers, experiments aimed for obtaining models of dividers were conducted. The inclination and roughness of ridge walls are important for ridge waveguide manufacture. Fig. 8 shows a photomicrography of waveguide on an InP substrate manufactured by the best etching mode [5]. 


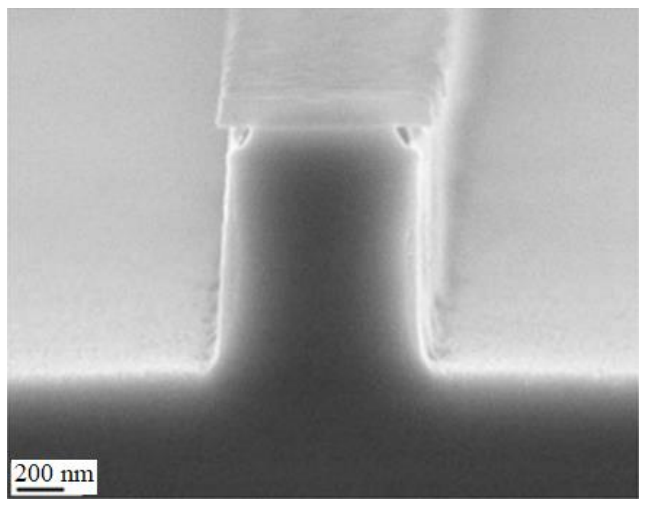

Fig. 8. Photomicrography of waveguide cross-section of etched InP/InGaAs heterostructure.

This mode allowed etching without using additional heating of the substrate. Photomicrography of Y- and MMI dividers on InP semiconductor substrate is presented in Fig. 9
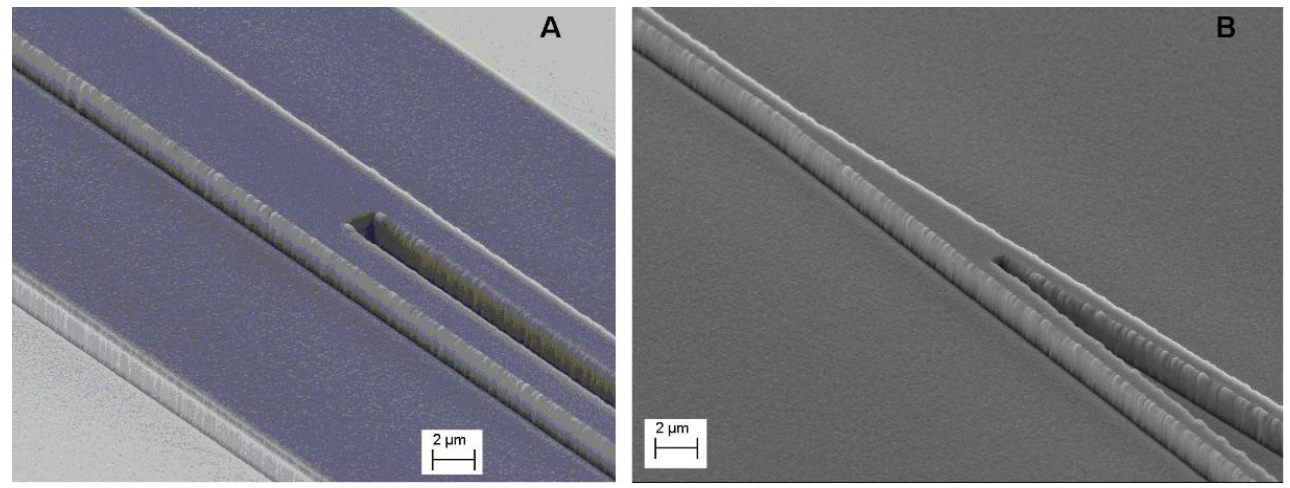

Fig. 9 Photomicrography of optic dividers on InP semiconductor substrate.

The obtained structures made possible to conduct research and prove experimentally the results of experiments of dividers electrical adjustment.

\section{Conclusion}

We investigated optic Y-and MMI dividers in this work. The research results showed that to increase the modulator reliability it is necessary to increase the accuracy of sizes of manufactured elements. Various methods have been proposed and investigated. Using the correction of the lithographic process will allow achieving an error of $\pm 0.1 \mu \mathrm{m}$. Using a control electrode will allow to adjust the division coefficient to $20 \%$, which minimizes lithographic errors during fabrication.

The study was conducted with financial support of the Ministry of Education and Science of the Russian Federation (agreement on the provision of subsidies No. 14.577.21.0281 of 10.23.2017, unique project identifier RFMEFI57717X0281).

\section{References}

1. J.L. Pleumeekers, R.P. Schneider, A. Mathuretal, Status and progress in InP optoelectronic processing. Toward higher levels of integration CS Mantech Conference. Vancouver, P. 115-11 (2006) 
2. J. Leuthold, Multimode Interference Couplers with Tunable Power Splitting Ratios, Journalvof lightwave technology, vol. 19, 5, p 700-707 (2015)

3. V.S. Arykov, P.E. Troyan, I.V. Kulinich, Osnovy elementnoi bazy VOLS v SVCh elektronike, Elektronnye sredstva i sistemy upravleniya, 2. s. 242-244. (2017)

4. M.V. Stepanenko, I.V. Kulinich, I.V. Yunusov, Optimizatsiya konstruktsii upravlyayushchikh SVCh elektrodov dlya elektroopticheskogo modulyatora na osnove kvantovorazmernogo effekta shtarka. Perspektivy razvitiya fundamental'nykh nauk Sbornik nauchnykh trudov XV Mezhdunarodnoi konferentsii studentov, aspirantov i molodykh uchenykh, S. 168-170 (2018)

5. S.V. Ishutkin, V.S. Arykov, Yu.S. Zhidik, P.E. Troyan, Plasma-chemical etching of InP / InGaAsheterostructures in inductively coupled Cl2 / Ar / N2 plasma for formation of optical waveguide structures. Reports of TUSUR 2018, vol. 21, 4. s 28-31 (2018) 